\title{
Impact of different approaches of primary care mental health on the prevalence of mental disorders
}

\author{
Leonardo Moscovici ${ }^{1}$, Joao Mazzoncini de Azevedo-Marques ${ }^{1}$, Lívia Maria Bolsoni $^{2}$, \\ Antonio Luiz Rodrigues-Junior ${ }^{1}$ and Antonio Waldo Zuardi ${ }^{2}$ \\ ${ }^{1}$ Department of Social Medicine, Ribeirão Preto Medical School, University of São Paulo, São Paulo, Brazil \\ ${ }^{2}$ Department of Neurosciences and Behavioral Sciences, Ribeirão Preto Medical School, University of São Paulo, \\ São Paulo, Brazil
}

\begin{abstract}
Aim: To compare the impact of three different approaches to primary care mental health on the prevalence of mental disorders. Background: Millions of people suffer from mental disorders. As entry point into the health service, primary healthcare plays an important role in providing mental health prevention and treatment. Methods: Random sample of households in three different areas of the city of Ribeirão Preto (state of São Paulo, Brazil) were selected, and 20 trained medical students conducted interviews using a mental health screening instrument, the Mini-Screening of Mental Disorders, and a sociodemographic datasheet. Primary care mental health was provided in each area through a specific approach. The influence of the area of residence and the socio-demographic variables on the prevalence of mental disorder was explored and analyzed by univariate binary logistic regression and then by a multiple logistic regression model. Findings: A total of 1545 subjects were interviewed. Comparison between the three areas showed a significantly higher number of people with mental disorders in the area covered by the primary care team that did not have physicians with specific primary care mental health training, even when this association was adjusted for the influence of age, education, and socio-economic status.

Our results suggest that residing in areas with family physicians with mental health training is associated with a lower prevalence of mental disorders.
\end{abstract}

Key words: mental disorders; mental health; primary care; public health

Received 10 December 2016; accepted 3 November 2017; first published online 5 December 2017

\section{Introduction}

Millions of people suffer from mental or emotional disorders (MED) worldwide [World Health Organization (WHO), 2008]. It is important to state that mental health problems and physical diseases are connected, where they can be either the cause or the consequence (WHO, 2008). By the year 2030, depression will likely be the second leading cause of disease burden in the world (WHO, 2008).

Correspondence to: Leonardo Moscovici, Department of Social Medicine, Ribeirão Preto Medical School, University of São Paulo, Rua Cezario Goncalves 181, Casa 10, Ribeirao Preto, São Paulo, CEP 14021-656, Brazil. Email: leoscovici@gmail.com
Most people with MED receive care in the primary health care (PHC). Even those individuals who are not in treatment have easier access to PHC than to specialized mental health services. However, only $49 \%$ of all PHC patients with MED are detected, and only about half of these are properly handled (Wittchen et al., 2003). It is clear that the diagnosis and adequate treatment of patients with MED in PHC could have a huge socio-economic impact, both individually and collectively. This is currently one of the most important global challenges to public health (Üstün and Sartorius, 1995; WHO, 2008).

One strategy that should be highlighted to provide better care for MED patients in PHC and

(C) Cambridge University Press 2017 
that is stirring interest in the world is shared care (SC) (in Brazil, it is given a specific term: Matrix Support) (Archer et al., 2012). SC is a concept that does not apply to a fixed model. It allows the inclusion of different programs. In general, one can conceptualize mental health SC as the clinical management of patients with MED carried out by PHC professionals in close collaboration with mental health professionals in primary care. Studies show beneficial effects of SC for MED patients (Gask and Croft, 2000; Goldberg, 2003; Bower and Gilbody, 2005; Gilbody et al., 2006; Kates and Mach, 2007; Katon et al., 2010; Cunha and Campos, 2011; Richards et al., 2013; Gonçalves et al., 2014). Because of the great diversity of interventions, it is necessary to evaluate the effectiveness of each SC model.

In Brazil, the SC model Matrix Support is integrated with the Brazilian primary care national plan of Family Health Strategy (FHS) (in Portuguese: Estratégia de Saúde da Família). FHS is a relatively new community-based specific PHC that started back in 1994. Each FHS team covers an area of $\sim 1000$ households (maximum of 4000 people) (Ministério da Saúde, 2016b). Currently, there are around 82 million Brazilians under the care of FHS teams, which corresponds to roughly $40 \%$ of all nation's population (Ministério da Saúde, 2016a).

The effectiveness of the Brazilian mental health $\mathrm{SC}$ was assessed by two qualitative studies in the same city (Campos et al., 2011; Onocko-Campos et al., 2012) and by a pilot quantitative study with a small number of patients, followed for one year (Moscovici et al., 2016). Although these initial studies indicated the beneficial effects of mental health SC, further studies with rigorous methods are still needed to confirm its effectiveness.

The present study aimed to compare the impact on MED prevalence among people from areas covered by health units with FHS, FHS with SC $(\mathrm{FHS}+\mathrm{SC})$, and with the Brazilian Traditional Care (TC). It is worth mentioning that all areas of this study had, in some way, an interaction with a medical school.

\section{Method}

\section{Study location}

The study was conducted between May and December of 2013 in Ribeirão Preto (RAO), a municipality situated in the northeast of the state of São Paulo, with $\sim 670000$ residents and a per capita annual income of approximately US\$10 000 (Instituto Brasileiro de Geografia e Estatística, 2010). In total, three areas of the city were selected for the study area, and all of them have PHC somehow connected to the Ribeirão Preto Medical School - University of São Paulo (RPMS). There is a distinct health strategy in each area, namely: FHS, FHS + SC, and TC.

\section{Description of teams and health strategies}

A Brazilian FHS team includes at least one family physician or general practitioner, one nurse, one nurse technician, and four to six community health workers (CHW). All FHS residents are registered in the health unit, and their households regularly receive visits from $\mathrm{CHW}$. Each $\mathrm{CHW}$ is in charge of a maximum of 750 people (or 150 families), and they have to visit each family at least once a month. Usually, a FHS team has six CHW and a limit of 4000 people in the coverage area (Ministério da Saúde, 2016b).

At the time of the study, the FHS + SC units had access to mental health specialists, who performed weekly consultation/liaison activities and provided specialized care in the FHS health unit facilities. These mental health specialists spent only a small part of their working hours seeing patients directly, an activity performed preferentially by family physicians.

Family physicians of both the FHS and FHS + SC teams had their training in family and community medicine specialization at RPMS. This training included 40 seminars of mental health $(2 \mathrm{~h}$ each seminar), psychiatric emergency internship in a general hospital, and participation in weekly counseling or liaison meetings with psychiatrists and/or mental health nurses (which also included joint consultation). The goals of the seminars were to provide education on psychiatric disorders and to integrate mental health into a patient-centered/ bio-psychosocial approach (Binotto et al., 2012).

At the time of this study, both areas of FHS (FHS and FHS + SC) had two teams each. The teams had, each one, around 2000 people in their coverage area and were composed of one family physician, one nurse, two nurse technicians, and four CHW.

The TC unit saw people from its area based on demand, and its staff was composed of two general 
practitioners, two pediatricians, one OB/GYN, two nurses, and five nurse technicians. They did not have specific mental health training during their specializations. It is important to point out that this TC health unit had five CHW, even though it did not function as an FHS. At the time of data collection, the TC health unit coverage area had $\sim 6000$ people.

\section{Subjects}

The study observed 1545 local residents over 18 years old and of both genders, who participated in this study as volunteers. All subjects lived in the area covered by one of the three healthcare strategies. Severe cognitive impairment cases were excluded from the sample. The participants were randomly selected from a household geographical information system. Every participant signed an informed consent form, as the study had been approved by the local ethical committee.

\section{Instrument}

The Mini-Screening of Mental Disorders (Mini-SMD)

The screening tool Mini-SMD is composed of nine items that assess four main diagnostic categories: depression, anxiety, alcohol and/or substance abuse, and psychotic disorders. This screening instrument is not, in a certain way, a new tool, but actually a compilation of well-established instruments. Explaining better, Mini-SMD was developed by the merge of four previously validated instruments: four items from PHQ-4 (Kroenke et al., 2009), one item from AUDIT item 3 (Meneses-Gaya et al., 2010), one item from CUDIT - item 1 (Annaheim et al., 2010), and three items from the APSS (Kelleher et al., 2011). Mini-SMD was validated in a PHC population (Bolsoni, 2015). In this study, receiver operating characteristic curves considering the presence or absence of any MED diagnosed by the MINI interview in Portuguese, validated in a Brazilian population (de Azevedo Marques and Zuardi, 2008), showed an area under the curve of 0.836 . Considering a cut-off point $>3$, the Mini-SMD showed a sensitivity of 0.8 and specificity of 0.75 . The concurrent validity was evaluated in relation to the Dartmouth Primary Care Cooperative Research Network (COOP-WONCA) charts - item feelings, a measure that showed similar psychometric characteristics as the Self-Reporting Questionnaire (SRQ-20) and World Health Organization - Five Well-Being Index (WHO-5) (de Azevedo Marques and Zuardi, 2011).

We also used a questionnaire that aimed to obtain the following data: gender, age, and socio-economic level. Socio-economic level was evaluated by the Brazilian Economic Classification Criteria (Brazilian Association of Research Companies, 2016), which uses an operational criterion based on existing goods in the households. The original five levels were grouped into three main categories to facilitate analysis.

\section{Procedure}

A total of 20 students from RPMS performed the interviews (using the Mini-SMD and collecting socio-demographic data). All students were trained and instructed with general information about the study (three workshops, with a total of $6 \mathrm{~h}$ ). Each student received an equal sample of households randomly selected to be visited in the three areas. At the time, they did not know to which health service the household had access.

An electronic version of the Mini-SMD and a socio-demographic datasheet were developed, allowing the students to use tablets and/or smartphones to collect data. All data were recorded offline and sent online afterwards to a common spreadsheet. In the field, interviewers sought the assigned addresses. When they failed to find residents in three different attempts, they visited the home immediately to the right. At first contact, students introduced themselves and provided information about the survey. They recorded all household members' names and their most convenient time to answer the interview. On that same visit, residents at home signed the informed consent form and were individually interviewed. Others not present were interviewed at subsequent visits (preferred time for residents), with prior appointment by phone. All residents of the selected households who met the inclusion criteria and agreed to participate were interviewed.

\section{Statistical analysis}

The $\chi^{2}$ test was used to compare the population's age and gender across study samples in each area. 
Univariate binary logistic regression analysis was used to determine the effect of the area and sociodemographic variables (gender, age, education, marital status, employment status, and socioeconomic level) on the occurrence of MED (Mini-SMD estimate: positive when score $>3$ ). Variables with $P<0.10$ (between 0.06 and 0.10 were interpreted as having borderline statistical significance) were included in a multiple logistic regression model (adjusted OR). Results are reported as unadjusted (crude) and adjusted odds ratios with a $95 \%$ CI. The statistical analysis was performed using the SPSS 20.0 software (IBM Corp., 2012).

\section{Results}

\section{Participants}

A total of 1545 subjects were interviewed: 487 people from the area with FHS, 549 from the area with FHS + SC, and 509 from the area with TC. Comparing the number of people from the study samples and actual population in relation to gender and age, the samples did not differ significantly regarding gender. However, in the FHS and TC areas, there was a higher percentage of subjects older than 60 years (Table 1).

\section{Estimated prevalence}

Table 2 shows the frequency of MED diagnosis and associations between MED and the following variables: area of residence, gender, age, education, marital status, employment status, and socioeconomic level.

The comparison of the FHS area versus the TC area showed a significantly higher number of MED in the latter. There was no significant difference when the FHS area with SC was compared with the FHS area without SC. Also, the two FHS areas together compared with the TC area showed a significantly lower prevalence of MED. The crude odds ratios were also significant for education and socio-economic level and with a trend towards significance for age. Variables with significant crude odds ratios or with a tendency towards significance were retested with a model of multiple logistic regression that included the variables area, age, education, and socio-economic status, confirming significance.
Table 1 Comparisons of age and gender between study samples and actual population in the three areas

\begin{tabular}{|c|c|c|c|c|}
\hline & $\begin{array}{l}\text { Sample } \\
n(\%)\end{array}$ & $\begin{array}{l}\text { Population } \\
n(\%)\end{array}$ & $\chi^{2}$ & $P$ value \\
\hline \multicolumn{5}{|l|}{$\mathrm{FHS}+\mathrm{SC}$} \\
\hline Male & $249(45.4)$ & $1711(44.1)$ & \multirow[t]{3}{*}{0.303} & \multirow[t]{2}{*}{$P=0.582$} \\
\hline Female & $300(54.6)$ & 2168 (55.9) & & \\
\hline \multicolumn{4}{|l|}{ Age } & \\
\hline $18-39$ & 180 (32.8) & $1443(37.2)$ & \multirow[t]{3}{*}{4.943} & \multirow[t]{3}{*}{$P=0.085$} \\
\hline $40-59$ & $190(34.6)$ & $1191(30.7)$ & & \\
\hline$>60$ & 179 (32.6) & $1246(32.1)$ & & \\
\hline \multicolumn{5}{|l|}{ FHS } \\
\hline \multicolumn{5}{|l|}{ Gender } \\
\hline Male & $231(47.4)$ & $1822(47.6)$ & \multirow[t]{2}{*}{0.005} & \multirow[t]{2}{*}{$P=0.944$} \\
\hline Female & $256(52.6)$ & $2006(52.4)$ & & \\
\hline \multicolumn{5}{|l|}{ Age } \\
\hline $18-39$ & $222(45.6)$ & $2180(56.9)$ & \multirow[t]{3}{*}{26.137} & \multirow[t]{3}{*}{$P<0.001$} \\
\hline $40-59$ & $205(42.1)$ & $1344(35.1)$ & & \\
\hline$>60$ & $60(12.3)$ & 301 (7.9) & & \\
\hline \multicolumn{5}{|l|}{$\mathrm{TC}$} \\
\hline \multicolumn{5}{|l|}{ Gender } \\
\hline Male & $223(43.8)$ & $2312(44.8)$ & \multirow[t]{3}{*}{0.179} & \multirow[t]{3}{*}{$P=0.672$} \\
\hline Female & $286(56.2)$ & $2850(55.2)$ & & \\
\hline \multicolumn{3}{|l|}{ Age } & & \\
\hline $18-39$ & $164(32.2)$ & $2110(40.9)$ & \multirow[t]{3}{*}{20.102} & \multirow[t]{3}{*}{$P<0.001$} \\
\hline $40-59$ & $161(31.7)$ & 1619 (31.3) & & \\
\hline$>60$ & $184(36.1)$ & $1433(27.8)$ & & \\
\hline
\end{tabular}

FHS = Family Health Strategy; $\mathrm{SC}=$ shared care; $\mathrm{TC}=$ traditional care.

${ }^{a}$ Data obtained from Primary Care Information System 2012 (in Portuguese: Sistema de informação da Atenção Básica)

These results suggested that residing in the areas with FHS coverage was associated with lower prevalence of MED, even when this association was adjusted for the influence of age, education, and socio-economic status. In this study, SC did not significantly influence the prevalence of MED in the FHS covered area.

The mean score of the Mini-SMD in the two FHS areas (3.18) compared to that of the TC area (3.56) was significantly lower $(T=1.953 ; P=0.05)$, suggesting that residents in FHS areas had lower symptoms of MED.

\section{Discussion}

The present study showed that areas assisted in primary care with the FHS model of care (either with or without SC) showed a significantly lower percentage of MED when compared with a TC 


\begin{tabular}{|c|c|c|c|c|}
\hline \multirow[b]{3}{*}{ Variables } & \multicolumn{2}{|c|}{ Mental disorder } & \multirow[b]{3}{*}{ OR (95\% Cl) [significance] } & \multirow[b]{3}{*}{ Adjusted OR (95\% Cl) [significance] } \\
\hline & \multicolumn{2}{|c|}{ Mini-SMD [ $n(\%)]$} & & \\
\hline & Negative & Positive & & \\
\hline \multicolumn{5}{|l|}{ Area $(\mathrm{FHS} \times \mathrm{TC})$} \\
\hline TC & $304(59.7)$ & $205(40.3)$ & $0.760(0.587-0.984)[P=0.037]$ & $0.752(0.572-0.989)[P=0.042]$ \\
\hline FHS & $322(66.1)$ & 165 (33.9) & & \\
\hline \multicolumn{5}{|l|}{ Area $(\mathrm{FHS} \times[\mathrm{FHS}+\mathrm{SC}])$} \\
\hline $\mathrm{FHS}+\mathrm{SC}$ & $359(65.4)$ & $190(34.6)$ & $1.033(0.799-1.336)[P=0.805]$ & - \\
\hline FHS & $322(66.1)$ & 165 (33.9) & & \\
\hline \multicolumn{5}{|l|}{ Area $(\mathrm{FHS}+[\mathrm{FHS}+\mathrm{SC}] \times \mathrm{TC})$} \\
\hline TC & $304(59.7)$ & $205(40.3)$ & $1.294(1.039-1.610)[P=0.021]$ & $1.257(1.002-1.575)[P=0.048]$ \\
\hline $\mathrm{FHS}+[\mathrm{FHS}+\mathrm{SC}]$ & $681(65.7)$ & $355(34.3)$ & & \\
\hline \multicolumn{5}{|l|}{ Gender } \\
\hline Male & $460(65.4)$ & $243(34.6)$ & $1.143(0.928-1.408)[P=0.210]$ & - \\
\hline Female & $525(62.4)$ & $317(37.6)$ & & \\
\hline \multicolumn{5}{|l|}{ Age } \\
\hline Median & 47 years & 45 years & $0.995(0.989-1.000)[P=0.072]$ & $0.982(0.982-0.995)[P=0.001]$ \\
\hline \multicolumn{5}{|l|}{ Schooling } \\
\hline Primary school incomplete & $215(58.7)$ & $151(41.3)$ & $1.578(1.135-2.194)[P=0.007]$ & $1.593(1.078-2.354)[P=0.019]$ \\
\hline Primary school & $164(62.1)$ & 100 (37.9) & $1.370(0.959-1.957)[P=0.083]$ & $1.222(0.834-1.791)[P=0.303]$ \\
\hline High school & $415(64.9)$ & $224(35.1)$ & $1.213(0.896-1.642)[P=0.212]$ & $1.100(0.807-1.501)[P=0.546]$ \\
\hline College degree & $191(69.2)$ & $085(30.8)$ & - & \\
\hline \multicolumn{5}{|l|}{ Marital status } \\
\hline Married or stable union & $599(65.5)$ & $315(34.5)$ & - & - \\
\hline Single & $246(61.3)$ & $155(38.7)$ & $1.198(0.940-1.528)[P=0.145]$ & - \\
\hline Divorced or widow & $138(60.8)$ & $89(39.2)$ & $1.226(0.909-1.654)[P=0.181]$ & - \\
\hline \multicolumn{5}{|l|}{ Employment status } \\
\hline Self-employed/employed & $592(63.3)$ & $343(36.7)$ & $1.034(0.806-1.327)[P=0.791]$ & - \\
\hline Housewife/student & $152(65.0)$ & $082(35.0)$ & $0.963(0.685-1.355)[P=0.829]$ & - \\
\hline Unemployed & $241(64.1)$ & $135(35.9)$ & - & \\
\hline \multicolumn{5}{|l|}{ Socio-economic level } \\
\hline $\mathrm{D} / \mathrm{E}$ & $043(55.1)$ & $035(44.9)$ & $1.720(1.078-2.745)[P=0.023]$ & $1.374(0.827-2.281)[P=0.220]$ \\
\hline C & $327(58.3)$ & $234(41.7)$ & $1.512(1.216-1.881)[P<0.001]$ & $1.360(1.069-1.730)[P=0.012]$ \\
\hline$A / B$ & $615(67.9)$ & $291(32.1)$ & - & - \\
\hline
\end{tabular}

$\mathrm{OR}=$ odds ratios; $\mathrm{Cl}=$ confidence intervals; Mini-SMD = Mini-Screening of Mental Disorders; $\mathrm{FHS}=$ Family Health Strategy; $\mathrm{TC}=$ traditional care; $\mathrm{SC}=$ shared care 
area. The logistic regression analysis confirmed that living in an area assisted by this particular model of care influenced the prevalence of MED significantly, even when results were adjusted for variables that also significantly affected prevalence, as was the case for age, education, and socioeconomic status. The influence on prevalence may be a consequence of an attenuation of symptoms (as suggested by the lower Mini-SMD mean score), leading to failure to reach the diagnostic threshold.

However, the Brazilian model of SC studied did not influence the prevalence of MED in the samples of this study. This observation contradicts the most consistent observation in the available literature, which points to the beneficial effects of SC in the progression of patients with MED (Gilbody et al., 2006; Archer et al., 2012; Moscovici, 2013; Moscovici et al., 2016). A few factors could explain this contradiction. First of all, to our knowledge, this was the first time a cross-sectional study used prevalence of MED as the outcome measure for evaluating the efficacy of SC. It is possible that the outcome measures mostly used in previous papers (ie, progression of MED in cohort studies) did not have a similar behavior to the prevalence of MED. In support of this hypothesis, a pilot longitudinal study evaluating patients with MED for a period of 12 months showed lower severity of symptoms in patients who were followed by FHS + SC teams when compared to patients from FHS teams without SC (Moscovici, 2013; Moscovici et al., 2016). Second, family physicians in the two areas covered by FHS (with and without SC) received their training in family and community medicine specialization at the same institution (RPMS), which had in their program a more extensive and complete mental health training. It is possible that this specific training overshadowed the impact of mental health SC in FHS and may be an obstacle for the generalization of our results.

Anyway, FHS with family physicians with proper mental health training seems to influence the prevalence of MED in the areas under their care. We noticed a lack of studies regarding the evaluation of SC in FHS, especially studies that quantitatively assessed outcomes of primary care patients.

Our study has other limitations. First, the MiniSMD was developed to be a brief screening tool. It is not a diagnostic instrument, although it has shown satisfactory psychometric characteristics regarding sensitivity and specificity. We were careful to describe our findings as an 'estimated' prevalence. Second, we only evaluated people from areas with health teams somehow linked to the University of São Paulo. All five health units from the three areas evaluated had the presence of medical and nursing students from this university. Third, we were not able to assess the work performed by the $\mathrm{CHW}$, since this was a population study outside the health units.

In conclusion, our FHS model - which includes the participation of family physicians with specific training in mental health seems to be a good strategy to: (a) promote mental health; (b) prevent MED, and; (c) lower the severity of symptoms, leading to failure to reach the diagnostic threshold of MED. Also, in this FHS model, the presence of SC did not influence the prevalence of MED. However, the peculiar characteristics of FHS in the present study might have masked the impact of SC. Our findings can support health authorities in designing future public health policies, including the increase of FHS coverage and encouraging adequate mental health training for family physicians.

\section{Acknowledgments}

The authors acknowledge the valuable advice from Prof. Afonso Dinis Costa Passos and the help of primary care professionals of the health units studied.

\section{Financial Support}

This study received grants from Fundação de Amparo à Pesquisa do Estado de São Paulo (FAPESP no. 2011/50740-5). AWZ is a recipient of productivity grants from Conselho Nacional de Desenvolvimento Cientifico e Tecnológico (CNPq).

\section{Conflicts of Interest}

All authors declare no conflicts of interest.

\section{Ethical Standards}

Study and consent forms were approved by the Research Ethics Committee of the University Hospital of the Ribeirão Preto Medical School University of São Paulo (HCFMRP-USP) under process number 151906. 


\section{Availability of data}

All data from this article are available through the corresponding author, including spreadsheets and signed consent forms.

\section{References}

Annaheim, B., Scotto, T.J. and Gmel, G. 2010: Revising the Cannabis Use Disorders Identification Test (CUDIT) by means of Item Response Theory. International Journal of Methods in Psychiatric Research 19, 142-55.

Archer, J., Bower, P., Gilbody, S., Lovell, K., Richards, D., Gask, L., Dickens, C. and Coventry, P. 2012: Collaborative care for depression and anxiety problems. Cochrane Database of Systematic Reviews 10, CD006525. http://www.ncbi.nlm.nih. gov/pubmed/23076925/n, http://doi.wiley.com/10.1002/1465

Binotto, A.L., dos Santos, L.L., Lourosa, Q.L., Sant'Anna, S.C., Zanetti, A.C.G., Forster, A.C. and Azevedo-Marques, J.M. 2012: Interface between the family health program \& mental health assistance: a strategy for care. Revista Brasileira de Medicina de Familia Comunidade 7, 83-89.

Bolsoni, L. 2015: Avaliação da confiabilidade e validade do Mini - Compêndio para Rastreamento de Transtornos Mentais (MINI-RTM). Master Degree. Ribeirão Preto, Brazil: University of São Paulo.

Bower, P. and Gilbody, S. 2005: Managing common mental health disorders in primary care: conceptual models and evidence base. BMJ: British Medical Journal 330, 839-842.

Brazilian Association of Research Companies. 2016: Brazilian criteria for economic classification. Retrieved 26 November 2016 from http://www.abep.org.

Campos, R.O., Gama, C.A., Ferrer, A.L., Santos, D.V.D.D., Stefanello, S., Trapé, T.L. and Porto, K. 2011: Saúde mental na atenção primária à saúde: estudo avaliativo em uma grande cidade brasileira. Ciência \& Saúde Coletiva 16, 4643-652.

Cunha, G.T. and Campos, G.W.S. 2011: Apoio matricial e atenção primária em saúde. Saude e Sociedade 20, 961-970.

de Azevedo Marques, J.M. and Zuardi, A.W. 2008: Validity and applicability of the Mini International Neuropsychiatric Interview administered by family medicine residents in primary health care in Brazil. General Hospital Psychiatry 30, 303-10.

de Azevedo-Marques, JM and Zuardi, AW. 2011: COOP/ WONCA charts as a screen for mental disorders in primary care. Ann Fam Med 9, 359-65.

Gask, L. and Croft, J. 2000: Methods of working with primary care. Advances in Psychiatric Treatment 6, 442-9.

Gilbody, S., Bower, P., Fletcher, J., Richards, D. and Sutton, A.J. 2006: Collaborative care for depression: a cumulative meta-analysis and review of longer-term outcomes. Archives of Internal Medicine 166, 2314-321.

Primary Health Care Research \& Development 2018; 19: 256-263
Goldberg, D. 2003: Psychiatry and primary care. World Psychiatry: Official Journal of the World Psychiatric Association (WPA) 2, 153-57.

Gonçalves, D.A., Mari, J.J., Bower, P., Gask, L., Dowrick, C., Tófoli, L.F., Campos, M., Portugal, F.B., Ballester, D. and Fortes, S. 2014: Brazilian multicentre study of common mental disorders in primary care: rates and related social and demographic factors. Cadernos de Saúde Pública 30, 623-32.

Instituto Brasileiro de Geografia e Estatística (IBGE). 2010: Cidades. Retrieved 26 November 2016 from http://cidades. ibge.gov.br/xtras/home.php.

Kates, N. and Mach, M. 2007: Chronic disease management for depression in primary care: a summary of the current literature and implications for practice. Canadian Journal of Psychiatry. Revue Canadienne de Psychiatrie 52, $77-85$.

Katon, W.J., Lin, E.H.B., Korff, M.V., Ciechanowski, P., Ludman, E.J., Young, B., Peterson, D., Rutter, C.M., McGregor, M. and McCulloch, D. 2010: Collaborative care for patients with depression and chronic illnesses. The New England Journal of Medicine 363, 2611-620.

Kelleher, I., Harley, M., Murtagh, A. and Cannon, M. 2011: Are screening instruments valid for psychotic-like experiences? A validation study of screening questions for psychotic-like experiences using in-depth clinical interview. Schizophrenia Bulletin 37, 362-69.

Kroenke, K., Spitzer, R.L., Williams, J.D.S.W. and Lowe, B. 2009: An ultra-brief screening scale for anxiety and depression: the PHQ-4. Psychosomatics 50, 613-21.

Meneses-Gaya, C., Zuardi, A.W., Loureiro, S.R., Hallak, J.E., Trzesniak, C., de Azevedo Marques, J.M., Machado-deSousa, J.P., Chagas, M.H., Souza, R.M. and Crippa, J.A. 2010: Is the full version of the AUDIT really necessary? Study of the validity and internal construct of its abbreviated versions. Alcoholism: Clinical and Experimental Research 34, 1417-424.

Ministério da Saúde. 2016a: DATASUS. Retrieved 26 July 2016 from http://tabnet.datasus.gov.br/cgi/tabcgi.exe?sih/ cnv/niuf.def.

Ministério da Saúde. 2016b: DAB. Retrieved 26 July 2016 from http://dab.saude.gov.br/portaldab/smp_como_funciona. php?conteudo=esf.

Moscovici, L., Azevedo-Marques, J.M. and Zuardi, A.W. 2016 : Integrated mental healthcare: outcomes from Brazilian primary care. European Journal for Person Centered Healthcare 4, 669-674.

Moscovici, L. 2013: Evaluation of psychometric properties and results from the application of the Brazilian version of the 'Mini International Neuropsychiatric Interview TRACKING' in users of the Family Health Strategy accompanied with or without collaborative care in mental health. Master Degree. Ribeirão Preto, Brazil: University of São Paulo.

Onocko-Campos, R.T., Campos, G.W.S., Ferrer, A.L., Corrêa, C.R.S., Madureira, P.R., Gama, C.A., Dantas, D.V. and Nascimento, R. 2012: Evaluation of 
innovative strategies in the organization of Primary Health Care. Revista de Saúde Pública 46, 43-50.

Richards, D.A., Hill, J.J., Gask, L., Lovell, K., ChewGraham, C., Bower, P., Cape, J., Pilling, S., Araya, R., Kessler, D., Bland, J.M., Green, C., Gilbody, S., Lewis, G., Manning, C., Hughes-Morley, A. and Barkham, M. 2013: Clinical effectiveness of collaborative care for depression in UK primary care (CADET): cluster randomised controlled trial. British Medical Journal 347, f4913.
Üstiin, T.B. and Sartorius, N. 1995. Mental illness in general health care: an international study. West Sussex, England: John Wiley \& SonsRetrieved from http://books.google.co. uk/books?id=RgnFHUmpVckC.

World Health Organization (WHO). 2008: Integrating mental health into primary care: a global perspective. Switzerland and Singapore: WHO Library.

Wittchen, H.-U., Mühlig, S. and Beesdo, K. 2003: Mental disorders in primary care. Dialogues in Clinical Neuroscience $5,115-28$. 